\title{
Experimental investigation of secondary and tertiary oil recovery from fractured porous media
}

\author{
P. Maroufi $\cdot$ Sh. Ayatollahi $\cdot$ H. Rahmanifard $\cdot$ \\ A. Jahanmiri • M. Riazi
}

Received: 28 October 2012/Accepted: 3 March 2013/Published online: 26 March 2013

(C) The Author(s) 2013. This article is published with open access at Springerlink.com

\begin{abstract}
Naturally fractured reservoirs (NFRs) contribute in large extent to oil and gas production to the ever increasing market demand of fossil energy. It is believed that the vertical displacement of oil during gas injection assisted by gravity drainage (GAGD) is one of the most efficient methods for oil recovery in these reservoirs. Hence, in this work, unconsolidated packed models of cylindrical geometry surrounded by fracture were utilized in order to perform a series of flow visualization experiments during which the contribution of different parameters such as the extent of matrix permeability, physical properties of oil (viscosity, density, and surface tension) and the withdrawal rate was studied. Furthermore, mutual effects of permeability, oil properties, and production rate on oil recovery efficiency through controlled and free fall gravity drainage processes were also investigated. Experimental results obtained from secondary and tertiary recovery experiments demonstrated that decreasing model permeability and increasing oil viscosity during secondary
\end{abstract}

Sh. Ayatollahi is on sabbatical leave from Shiraz University, P.O. Box 71345-1719, Shiraz, Iran.

P. Maroufi · Sh. Ayatollahi $(\bowtie) \cdot H$. Rahmanifard · M. Riazi EOR Research Center, School of Chemical and Petroleum Engineering, Shiraz University, Zand Street, P.O. Box 713451719, Shiraz, Iran

e-mail: shahab@shirazu.ac.ir

\section{A. Jahanmiri}

School of Chemical and Petroleum Engineering, Shiraz

University, Zand Street, P.O. Box 713451719, Shiraz, Iran

Present Address:

Sh. Ayatollahi

Sharif University of Technology, Tehran, Iran recovery process reduced the recovery efficiency for all production rates, while under tertiary recovery process these phenomena lead to more oil production for all production rates.

Keywords Waterflooding - Gravity drainage · Production rate $\cdot$ Permeability $\cdot$ Oil physical properties
Abbreviations
CGD Controlled gravity drainage
FF Free fall
FFGD Free fall gravity drainage
GB Gas breakthrough
IOIP Initial oil in place
RF Recovery factor

\section{List of symbols}

$g \quad$ Gravity constant $\left(\mathrm{m} / \mathrm{s}^{2}\right)$

$H_{\mathrm{ob}} \quad$ The height of oil bank

$K \quad$ Absolute permeability (darcy)

$k \quad$ Effective reservoir permeability (darcy)

$M \quad$ Mobility ratio (dimensionless)

$N_{\mathrm{gv}} \quad$ Gravity number (dimensionless)

$N_{\mathrm{c}} \quad$ Capillary number (dimensionless)

$S_{\text {oi }} \quad$ Initial oil saturation

$S_{\text {or }} \quad$ Residual oil saturation

$S_{\text {wc }} \quad$ Connate water saturation

$T_{\mathrm{GB}} \quad$ Gas breakthrough time (min)

$V_{\mathrm{pg}} \quad$ Pore velocity of the gas-liquid interface

$v_{\mathrm{o}} \quad$ Oil production velocity (pump suction)

$\mu \quad$ Fluid viscosity ( $\mathrm{Pa} \mathrm{s}$ )

$\mu_{\mathrm{o}} \quad$ Oil viscosity ( $\left.\mathrm{Pa} \mathrm{s}\right)$

$\rho_{\mathrm{o}} \quad$ Oil density $\left(\mathrm{g} / \mathrm{cm}^{3}\right)$

$\rho_{\mathrm{g}} \quad$ Gas density $\left(\mathrm{g} / \mathrm{cm}^{3}\right)$

$\sigma_{\text {og }}$ Gas-oil interfacial tension $(\mathrm{mN} / \mathrm{m})$ 


\section{Subscripts \\ F Fracture \\ i Initial \\ g Gas \\ o Oil \\ r Residual \\ w Water}

\section{Introduction}

There are three classifications of oil production in petroleum reservoirs which are: primary, secondary, and tertiary. In primary recovery process, depletion occurs under natural reservoir pressure (Green and Willhite 1998). While in secondary recovery process by water or gas injection into the reservoir, partial or full pressure maintenance and oil displacement toward the production well are achieved. Literature review in previous years shows that waterflooding has been the most successful method (especially for water-wet fractured media) which is efficient in many reservoirs (Babadagli 2003). However, even in this case significant amount of oil (about two trillion barrels worldwide) is still trapped in the reservoir (Rostami 2009).

Therefore, in order to recover the residual oil, utilization of tertiary oil recovery procedures which are mainly gas or chemical injections and the use of thermal recovery are essential. Past experiences demonstrated that this huge amount of oil remaining in the reservoirs could be recovered effectively by gas-injection methods (Rostami 2009; Rezaveisi et al. 2010; Kulkarni 2005). However, low viscosity of injected gases led to unfavorable mobility ratios and severe gas-oil gravity segregation with large un-swept reservoir volume. Consequently, despite their high microscopic displacement efficiencies, especially under miscible conditions, volumetric sweep efficiency of these EOR processes is their major shortcoming (Hinderaker et al. 1996; Van Pollen 1980). Thus, in order to improve sweep efficiency of gas-injection processes, water alternating gas (WAG) has been widely practiced with simultaneous decrease of gas consumption. Similarly, unfavorable mobility ratio in addition to the increased mobile water saturation which causes water shielding ${ }^{1}$ result in poor recovery in WAG process (Kulkarni and Rao 2006).

Another procedure is the drainage of oil by gas injection under gravity forces by which recoveries of $85-95 \%$ of the initial oil in place (IOIP) were reported in the field (Carlson 1988; Johnston 1988; Fassihi and Gillham 1993; Kantzas et al. 1988a). In fact, the density difference between oil and gas within the matrix/fracture causes this high amount of oil

\footnotetext{
${ }_{1}$ Water films prevent oil and gas coming into direct contact and for miscible gas injection it delays the onset of miscibility.

recovery efficiency (Nabipour et al. 2007). For the first time, the idea of recovering trapped oil after waterflooding process was considered by Carlson (1988) in a gas-injection project in the Hawkins field. Similarly, Kantzas et al. (1988b) and Chatzis et al. (1988) performed some gravity drainage experiments. In their experiments, they showed that gravity drainage has an important role in gas-injection process which was called gas-assisted gravity drainage process (GAGD).

Based on the types of production mechanism, the GAGD process could be divided into three types: free fall gravity drainage (FFGD), forced gravity drainage (FGD), and controlled gravity drainage (CGD) (Zendehboudi et al. 2011). There are several parameters including rock permeability, spreading coefficients ${ }^{2}$ of the involved fluids, injection or production rate, oil viscosity, three phase relative permeabilities, and capillary pressure which affect the performance of GAGD. Since then, the influence of these parameters on the ultimate oil recovery during GAGD process has been investigated by several authors. Terwillinger et al. (1951) showed insignificant role of maximum theoretical gravity drainage rate, and a strong dependency between ultimate recovery and production rate. In contrast, the same or even better ultimate oil recovery at higher production rates in controlled gravity drainage (CGD) were reported by Chatzis and Ayatollahi (1993). In their experiment, homogeneous, water-wet unconsolidated media and positive oil spreading coefficients were utilized. In another work, they also reported the effect of layered permeability type of heterogeneous pore structure on the production characteristics of the gravity-assisted inert gasinjection process (Chatzis and Ayatollahi 1995). In addition, Zendehboudi and Chatzis (2008) recently utilized CGD process in a fractured porous media in which the effect of fracture aperture, matrix height and permeability, well spacing and fluid viscosity on the magnitude of newly defined variables: critical pumping rate and also maximum possible withdrawal rate were investigated.

So far, many efforts have been made to investigate the efficient parameters on the recovery of residual oil in fractured media by gravity drainage process (Dullien et al. 1990; Da Sle and Guo 1990; Dean and Lo 1988; Paul and Zoback 2007; Quintard and Whitaker 1996; Rossen and Shen 1987; Salimi and Bruining 2008). However, there are still challenging topics related to the application of GAGD process in fractured media, which lead to contradictory results such as physical properties of oil (viscosity, density, and surface tension), production rate, and matrix permeability. Consequently, by conducting several experimental studies and analyzing the results using theoretical and analytical aspects, this study attempts to perform a parametric sensitivity analysis in order to determine the effects of matrix permeability

\footnotetext{
${ }^{2}$ If a drop of oil is placed on a flat liquid substrate its behavior is determined by the initial spreading coefficient $S: S=\sigma_{\mathrm{wo}}+\sigma_{\mathrm{go}}$.
} 


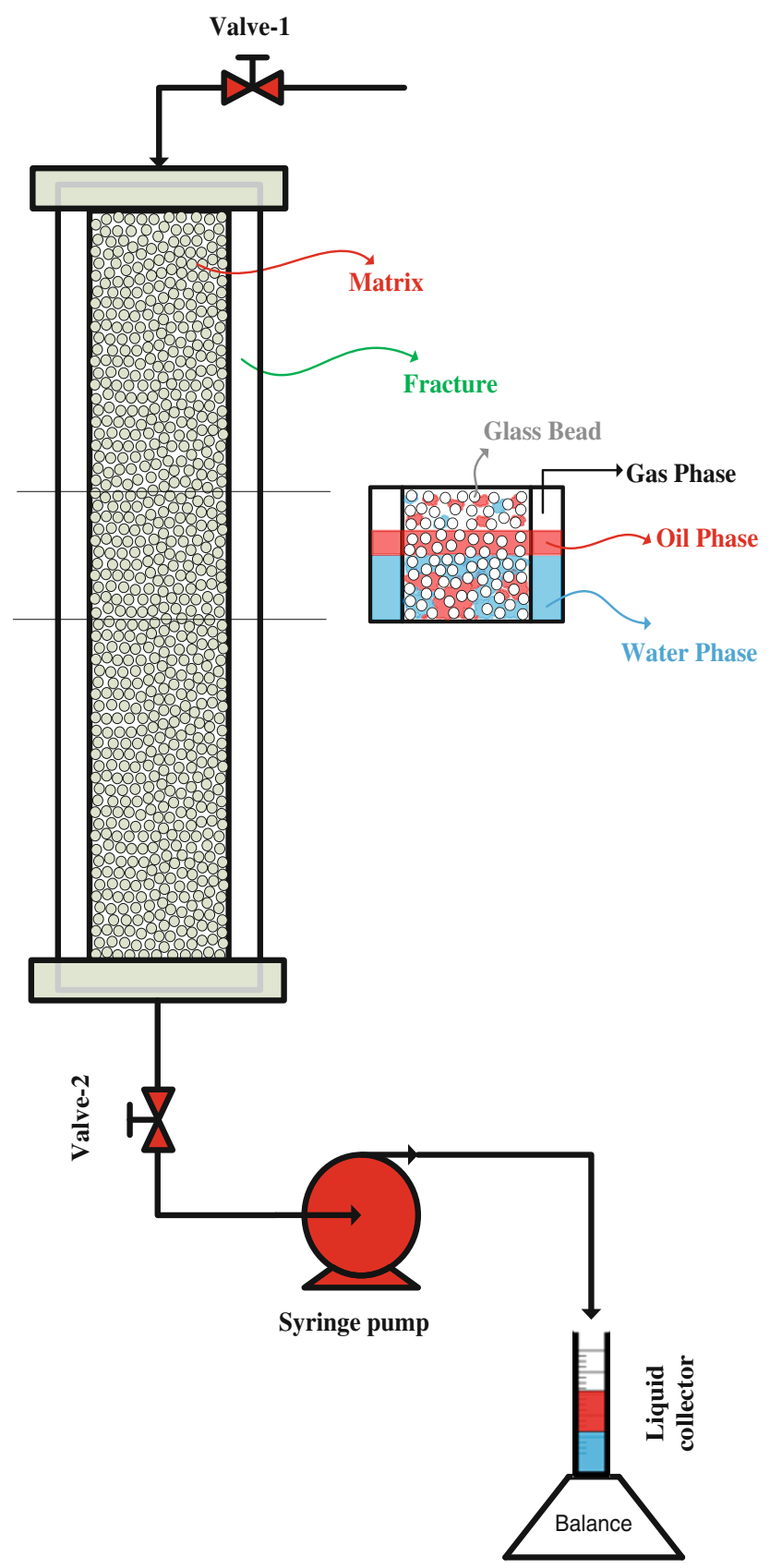

Fig. 1 Schematic diagram of the experimental setup

and fluid physical properties on ultimate oil recovery through secondary and tertiary recovery processes (waterflooding and CGD mechanisms, respectively). Moreover, the performance of CGD under different production rates are also compared to the FFGD mechanisms.

\section{Experimental work}

In this section, details of the experimental setup, test fluids, and experimental procedures are presented and the results are discussed accordingly.
Table 1 Physical properties of the core holder setup

\begin{tabular}{ll}
\hline Length of inner holder & $59 \mathrm{~cm}$ \\
Total length of outer holder & $60 \mathrm{~cm}$ \\
Inner diameter of outer holder & $4 \mathrm{~cm}$ \\
Outer diameter of inner holder & $3.9 \mathrm{~cm}$ \\
Inner diameter of inner holder & $3 \mathrm{~cm}$ \\
Fracture permeability & $22.9 \mathrm{~m}^{2}$ \\
Fracture aperture & $0.5 \mathrm{~mm}$ \\
Model 1 & \\
Absolute permeability of matrix & $8.7 \mathrm{darcy}$ \\
Porosity & $39 \%$ \\
Size distribution of glass beads & $0.5-0.8 \mathrm{~mm}$ \\
Model 2 & \\
Absolute permeability of matrix & $5 \mathrm{darcy}$ \\
Porosity & $37.2 \%$ \\
Size distribution of glass beads & $0.31-0.37 \mathrm{~mm}$ \\
\hline * Calculated using cubic law (Paillet et al. 1987)
\end{tabular}

Experimental setup

Figure 1 shows schematic diagrams of the experimental setup used in this study. This novel model consists of two parts: the inner core holder placed within the outer core holder in which a bed of well-screened glass beads was carefully packed by means of a vibrating table with a slim size distribution. The annular space between two holders is simulating vertical fracture. In order to join matrix and fracture, using laser technology the inner core holder was perforated. The number of holes was 187 per each $10 \mathrm{~cm}$ of the core holder height and their diameters were $0.1 \mathrm{~mm}$ which was significantly smaller than glass beads diameters $(0.5-0.8 \mathrm{~mm})$. The properties of the fractured model are given in Table 1. It is essential to say that matrix porosity was determined by using a porosity meter apparatus and it was concluded that all systems had approximately the same porosity. Additionally, steady-state permeability measurement technique was used to measure the permeability of different employed models.

\section{Test fluids}

Gravity drainage tests were performed using dyed $n$-heptane and gasoil with Sudan-red, air, and distillated water to simulate oil phases, gas phase, and water phase, respectively. The test fluids' physical properties are shown in Table 2.

\section{Drainage experimental procedure}

A set of 15 different CGD and FFGD tests were carried out for two different matrix permeabilities and oil fluids with 
Table 2 Physical properties of test fluids

\begin{tabular}{llll}
\hline Test fluids & $\begin{array}{l}\text { Density } \\
\left(\mathrm{g} / \mathrm{cm}^{3}\right)\end{array}$ & $\begin{array}{l}\text { Surface tension } \\
(\mathrm{mN} / \mathrm{m})\end{array}$ & $\begin{array}{l}\text { Viscosity } \\
(\mathrm{Pa} \mathrm{s})\end{array}$ \\
\hline Water & 1 & 72.8 & $8.9 \mathrm{E}-4$ \\
$n$-Heptane & 0.7 & 24.1 & $3.9 \mathrm{E}-4$ \\
Gasoil & 0.9 & 30.6 & $4.6 \mathrm{E}-4$ \\
Air & $1.2 \mathrm{E}-3$ & - & $1.8 \mathrm{E}-5$ \\
\hline
\end{tabular}

five various production rates. In order to check the repeatability of the tests and verify the accuracy, some of the tests were repeated several times and the average results were used by the end. The procedure involved the following steps:

1. The glass beads were packed in the inner core holder (matrix), using a vibrating table which was then transferred into the outer core holder.

2. Prior to saturating the model with any liquid, the air packets in the matrix part of the model were flushed out using several pore volumes of $\mathrm{CO}_{2}$.

3. In order to saturate the system with water, at least four pore volumes of distilled water were injected from the bottom at very low rates to ensure complete saturation of the matrix block. In this step, $\mathrm{CO}_{2}$ molecules within the pores were dissolved in water and consequently the model is fully saturated with water.
4. In the next step, the dyed oil ( $n$-heptane or gasoil) was injected from the top of the column using a syringe pump while the water was displaced from the end of the column. The injection process continued until the water saturation reached the irreducible state. The transparency of the model and dyed oil allowed us to monitor the oil-water interface during the oil flooding. Initial oil in place and the connate water saturation at this step were measured by volumetric balance.

5. For the secondary recovery process, water was injected at constant rate of $11.66 \mathrm{cc} / \mathrm{min}$ from the bottom of the model. The volume of oil produced from the top was measured volumetrically. The water injection was continued till no more oil was produced. The amount of residual oil was calculated by subtracting the volume of oil produced by waterflooding process from the volume of initial oil in place (determined in step 4).

6. Finally, by opening the top valve of the column to atmospheric air and draining liquid from bottom valve at constant rate with a syringe pump, CGD process was started. Oil bank formation in the column and the oil recovery up to gas breakthrough at different production rates were the main goals of this investigation during CGD process. Besides the CGD mechanism, FFGD tests were also utilized to compare the outcomes. In performing FFGD experiments, all steps prior to step 6 were the same as CGD tests. However, in the final step during FFGD tests, the top

Table 3 Results of controlled and free fall gravity drainage experiments for 15 tests

\begin{tabular}{|c|c|c|c|c|c|c|c|c|c|c|c|c|c|c|}
\hline \multirow[t]{2}{*}{$\begin{array}{l}\text { Experiment } \\
\text { number }\end{array}$} & \multirow[t]{2}{*}{$\begin{array}{l}\text { Permeability } \\
\text { (darcy) }\end{array}$} & \multirow[t]{2}{*}{$\begin{array}{l}\text { Oil } \\
\text { phase }\end{array}$} & \multicolumn{2}{|c|}{$\begin{array}{l}\text { Initial } \\
\text { conditions }\end{array}$} & \multicolumn{2}{|c|}{ Waterflooding } & \multicolumn{7}{|l|}{ GAGD } & \multirow[t]{2}{*}{$\begin{array}{l}\text { Ultimate } \\
\text { RF (\%) }\end{array}$} \\
\hline & & & $\begin{array}{l}S_{\mathrm{wc}} \\
(\%)\end{array}$ & $\begin{array}{l}S_{\mathrm{oi}} \\
(\%)\end{array}$ & $\begin{array}{l}\mathrm{RF} \\
(\%)\end{array}$ & $\begin{array}{l}S_{\text {orw }} \\
(\%)\end{array}$ & $\begin{array}{l}\text { Withdrawal } \\
\text { rate } \\
(\mathrm{cc} / \mathrm{min})\end{array}$ & $\begin{array}{l}\mathrm{RF} \text { at } \\
\mathrm{GB} \\
(\%)\end{array}$ & $\begin{array}{l}H_{\mathrm{ob}} \\
(\mathrm{cm}) \text { in } \\
\text { fracture }\end{array}$ & $\begin{array}{l}T_{\mathrm{GB}} \\
(\mathrm{min})\end{array}$ & $\begin{array}{l}S_{\mathrm{or}} @ \mathrm{gb} \\
(\%)\end{array}$ & $\begin{array}{l}\text { RF } \\
\text { after } \\
\text { GB } \\
(\%)\end{array}$ & $\begin{array}{l}\text { Tertiary } \\
\text { RF (\%) }\end{array}$ & \\
\hline 1 & 8.7 & $n-\mathrm{C}_{7}$ & 23.36 & 76.64 & 89.43 & 10.57 & 0.1 & 4.42 & 6 & 2088 & 6.14 & 0.24 & 4.66 & 94.09 \\
\hline 2 & 8.7 & $n-\mathrm{C}_{7}$ & 26.04 & 73.96 & 88.53 & 11.47 & 1 & 3.33 & 5 & 157 & 9.53 & 2.23 & 5.56 & 94.09 \\
\hline 3 & 8.7 & $n-\mathrm{C}_{7}$ & 26.4 & 73.6 & 88.42 & 11.58 & 10 & 2.2 & 4 & 18.3 & 9.39 & 3.15 & 5.35 & 93.77 \\
\hline 4 & 8.7 & $n-\mathrm{C}_{7}$ & 23.4 & 76.6 & 87.02 & 12.98 & 29 & 2.03 & 3.5 & 7.3 & 10.94 & 3.18 & 5.21 & 92.23 \\
\hline 5 & 8.7 & $n-\mathrm{C}_{7}$ & 25.97 & 74.03 & 86.55 & 13.45 & $\mathrm{FF}$ & 1.96 & 0 & 0.2 & 10.81 & 5.57 & 7.53 & 94.08 \\
\hline 6 & 5 & $n-\mathrm{C}_{7}$ & 38.47 & 61.53 & 75.05 & 24.95 & 0.1 & 3.7 & 13 & 1476 & 21.25 & 3.43 & 7.13 & 82.18 \\
\hline 7 & 5 & $n-\mathrm{C}_{7}$ & 39.5 & 60.5 & 75.5 & 24.5 & 1 & 2.1 & 7 & 132 & 22.4 & 3.77 & 5.87 & 81.37 \\
\hline 8 & 5 & $n-\mathrm{C}_{7}$ & 41.27 & 58.73 & 75.12 & 24.88 & 10 & 1.2 & 5 & 8.3 & 23.68 & 4.81 & 6.01 & 81.13 \\
\hline 9 & 5 & $n-\mathrm{C}_{7}$ & 41.89 & 58.11 & 74.45 & 25.55 & 29 & 1 & 4 & 1.6 & 26 & 5.34 & 6.34 & 80.79 \\
\hline 10 & 5 & $n-\mathrm{C}_{7}$ & 40.59 & 59.41 & 74.77 & 23 & $\mathrm{FF}$ & 0.7 & 0 & 0.2 & 22.3 & 7.4 & 8.1 & 82.87 \\
\hline 11 & 8.7 & Gasoil & 24.13 & 75.87 & 83.11 & 16.89 & 0.1 & 8.4 & 11 & 1585 & 8.49 & 2.7 & 11.1 & 94.21 \\
\hline 12 & 8.7 & Gasoil & 24.42 & 75.58 & 83.84 & 16.16 & 1 & 5.8 & 6 & 143 & 10.36 & 4.2 & 10 & 93.84 \\
\hline 13 & 8.7 & Gasoil & 26.33 & 73.67 & 84.14 & 15.86 & 10 & 4.9 & 5 & 17.6 & 10.96 & 5.58 & 10.48 & 94.62 \\
\hline 14 & 8.7 & Gasoil & 24.18 & 75.82 & 84.21 & 15.79 & 29 & 3.6 & 4 & 2.5 & 12.19 & 8.04 & 11.64 & 95.85 \\
\hline 15 & 8.7 & Gasoil & 23.5 & 76.5 & 83.27 & 16.73 & $\mathrm{FF}$ & 2 & 0 & 0.2 & 14.73 & 9.94 & 11.94 & 95.21 \\
\hline
\end{tabular}


and bottom valves of the model were opened suddenly to atmosphere.

It is essential to say that during tertiary gravity drainage (CGD/FFGD) tests; oil and water production, gas-liquid interfaces and oil bank formation within the matrix and fracture were monitored carefully. In addition, the results are classified into two different periods: before gas breakthrough and after gas breakthrough, which are presented in the next section.

\section{Experimental results and discussion}

Table 3 summarizes the main results of 15 tests from which many of the conclusions have been directly derived. It is wise mentioning that wettability (water-wet) and the water injection rate in waterflooding (step 5) are the same for all tests.

The effect of permeability and oil physical properties on waterflooding performance

As it is presented in Table 3, to check the effect of permeability for the case with $n$-heptane, two media with different permeabilities were tested. Prior to waterflooding, the fracture was fully saturated with oil while the matrix was filled with oil and connate water. Because of the higher permeability of fracture, injecting water from bottom valve of the model, swept oil in fracture in the first stage and then, expelled oil from the matrix by penetrating from the bottom and through perforations of the inner core holder under co-current imbibition mechanism. As the size of the glass beads decreases (reduction in permeability), the pore radii reduce which causes the increase of capillary forces, and higher connate water saturation (from $21 \%$ in the medium with the permeability of 8.7 darcy to $41 \%$ for the medium of 5 darcy). Therefore, during the waterflooding of lower permeability cases, due to the higher capillary pressure of smaller pores, water went through smaller pores while bypassing some larger ones. Hence, in low-permeable models as compared to the cases with higher permeability, shorter water breakthrough time and lower recovery factor were achieved. (see Fig. 2a).

The performance of waterflooding process for two different oil phases ( $n$-heptane and gasoil) is compared in Fig. 2b. All properties of two sets of experiments except the oil physical properties such as viscosities, IFT(s) and densities were the same. It is generally accepted that the mobility ratio plays an important role in maximizing the efficiency of any EOR process which is defined as follows (Green and Willhite 1998):
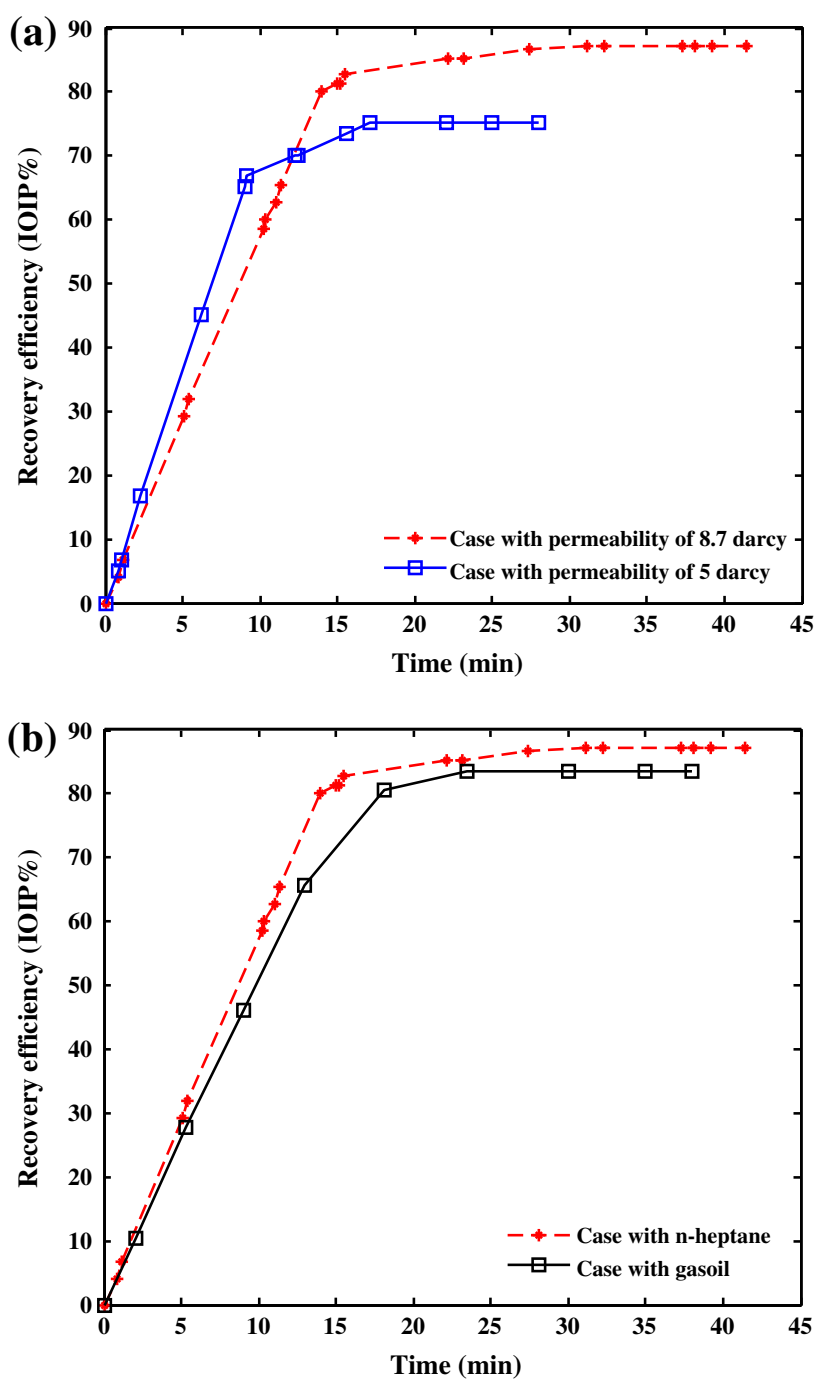

Fig. 2 Oil recovery of secondary recovery process for a cases with different permeabilities, and $\mathbf{b}$ cases with different physical properties of oil along the production time

$M=\frac{\left(\frac{k}{\mu}\right)_{\text {Displacingfluid }}}{\left(\frac{k}{\mu}\right)_{\text {Displacingfluid }}}$,

where oil and water phase are displaced and displacing fluids, respectively. Because of the similarities of displacing fluid and matrix characteristics, the mobility ratios for these tests were directly dependent on the displaced phase viscosity (oil phase). Consequently, higher oil viscosity caused larger mobility ratio which results in unstable front movement (water fingering phenomenon), shorter gas breakthrough time, and lower oil recovery factor (see Fig. 2b). Moreover, due to the higher density of gasoil as compared to $n$-heptane (see Table 2), for the case of gasoil, water phase is not capable of efficiently sweeping oil in the matrix and alternatively, chose its route through the 
fracture with lower resistance to the flow as compared to the matrix block. Therefore, an incremental trend of oil viscosity leads to early occurrence of water breakthrough. (see Fig. 2b).

The effect of permeability, physical oil properties, and production rate on the performance of tertiary recovery process

During the early stages of production at a constant withdrawal rate, because of low-resistance force in fracture against flow, at first the liquid was pumped from fracture, and consequently, the fracture was invaded immediately by gas. Therefore, the liquid head (gas-liquid interface) inside the fracture dropped and at a particular time due to the pressure difference $(\Delta P)$ between top and bottom of the model, it became feasible for gas to begin to enter the matrix, while it was continuing to flow in fracture (Maroufi

Table 4 Oil recovery factors and gravity numbers for different withdrawal rates at gas breakthrough for two different permeabilities

\begin{tabular}{lllr}
\hline Permeability (darcy) & Production rate (cc/min) & RF @ $T_{\mathrm{GB}}$ & $N_{\mathrm{gv}}$ \\
\hline 8.7 & 0.1 & 4.42 & 113.6 \\
& 1 & 3.33 & 11.4 \\
& 10 & 2.2 & 1.1 \\
29 & 2.03 & 0.4 \\
5 & Free fall & 1.96 & 0.05 \\
& 0.1 & 3.7 & 66.2 \\
& 1 & 2.1 & 6.6 \\
& 10 & 1.2 & 0.7 \\
& 29 & 1 & 0.2 \\
& Free fall & 0.7 & 0.02
\end{tabular}

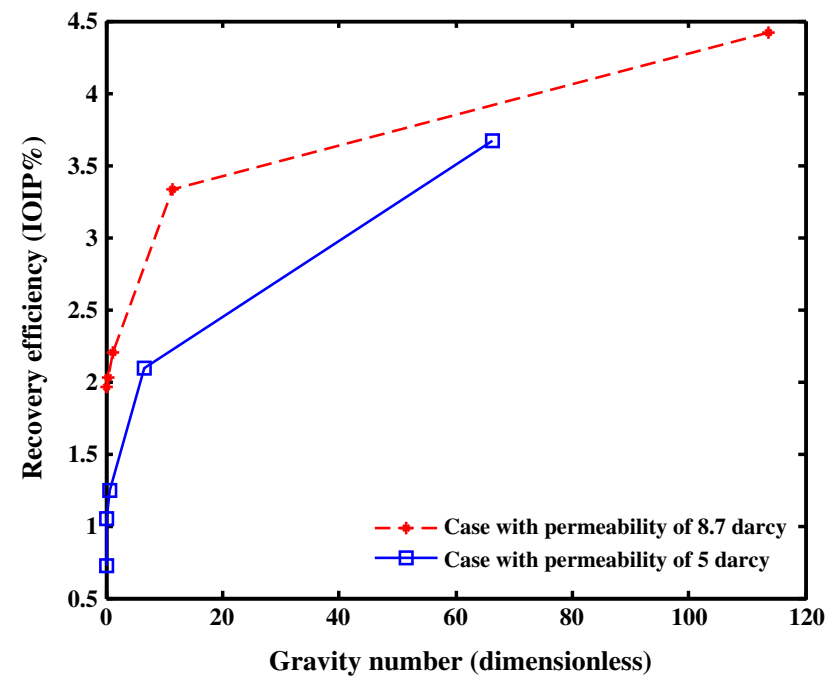

Fig. 3 Recovery efficiencies for two different models versus the gravity numbers at gas breakthrough et al. 2012). As a result, due to the equal gas invasion driving force in both matrix and fracture, liquid drainage from the matrix began and joined the flux from fracture. Thus, in order to have a better investigation of the influence of withdrawal rate on oil recovery at gas breakthrough and thereafter, the results of CGD processes at five different production rates $0.1,1,10$, and $29 \mathrm{cc} / \mathrm{min}$ and FFGD are presented. These tests were performed to find the effect of withdrawal rate on two different models (Experiment numbers 1-5 and 6-10) and two types of oil phase (Experiment numbers 1-5 and 11-15).

\section{Recovery up to gas breakthrough}

The effect of permeability During waterflooding process (step 5) due to the negligible capillary pressure and high permeability of fracture, the oil in the fracture part was completely drained instantly $\left(S_{\text {orf }}=0\right)$. However, there are still discontinued oil blobs in the matrix part, which are going to be produced by gas injection (step 6) under gravity drainage process (Chatzis and Ayatollahi 1995). Table 4 presents the oil recovery for various oil production rates at gas breakthrough for two different permeabilities (8.7 and 5 darcy). As is shown, increasing the production rate reduces the oil recovery at gas breakthrough for both systems. The reason for this behavior is that, at higher recovery rates higher permeability of the fracture compared to the matrix leads to very high gas velocity in the fracture, which prevents gas from entering the matrix to reconnect the oil ganglia for more oil recovery during tertiary process. On the other hand, as the capillarity intensifies in lower permeable cases, the chance for oil to remain in the matrix part also increases which results in early gas breakthrough and lower recovery factors as compared to cases with higher permeability.

In order to compare oil recoveries at gas breakthrough in systems with different permeabilities, Chatzis and Ayatollahi (1993) took gravity number $\left(N_{\mathrm{gv}}\right)$ as a basis for measuring average oil velocity by film flow in the gasinvaded zone due to gravity forces. This number is proportional to $K \Delta \rho_{\mathrm{og}} g / \mu_{\mathrm{o}}$, and to the pore velocity of the oil bank at the gas-oil contact ( $V_{\mathrm{pg}}$ set by viscous pressure gradients). Therefore, the gravity number that is defined by the following equation could also be used to justify what was found from the tests presented here (Hagoort 1980; Ayatollabi 1994):

$N_{\mathrm{gv}}=\frac{K \Delta \rho_{\mathrm{og}} g}{\mu_{\mathrm{o}} V_{\mathrm{pg}}}$.

where $K$ is the absolute permeability, $V_{\mathrm{pg}}$ is the experimentally measured pore velocity of the gas-liquid interface, $\mu_{\mathrm{o}}$ is the oil viscosity. Moreover, since the pore velocity of the gas-oil contact is not determined 
Table 5 Oil recovery factors and capillary numbers for two oil phases at different withdrawal rates at gas breakthrough

\begin{tabular}{|c|c|c|c|c|c|}
\hline Oil phase & Viscosity (Pa s) & Surface tension $(\mathrm{mN} / \mathrm{m})$ & Production rate $(\mathrm{cc} / \mathrm{min})$ & $\mathrm{RF} @ T_{\mathrm{GB}}$ & $N_{\mathrm{C}}$ \\
\hline \multirow[t]{5}{*}{$n$-Heptane } & $3.9 \mathrm{E}-4$ & 24.1 & 0.1 & 4.42 & $2.1 \mathrm{E}-8$ \\
\hline & & & 1 & 3.33 & $2.1 \mathrm{E}-7$ \\
\hline & & & 10 & 2.2 & $2.1 \mathrm{E}-6$ \\
\hline & & & 29 & 2.03 & $6.1 \mathrm{E}-6$ \\
\hline & & & Free fall & 1.96 & $5.1 \mathrm{E}-5$ \\
\hline \multirow[t]{5}{*}{ Gasoil } & $4.6 \mathrm{E}-4$ & 30.6 & 0.1 & 8.4 & $2 \mathrm{E}-8$ \\
\hline & & & 1 & 5.8 & $2 \mathrm{E}-7$ \\
\hline & & & 10 & 4.9 & $2 \mathrm{E}-6$ \\
\hline & & & 29 & 3.6 & $5.7 \mathrm{E}-6$ \\
\hline & & & Free fall & 2 & $2.9 \mathrm{E}-5$ \\
\hline
\end{tabular}

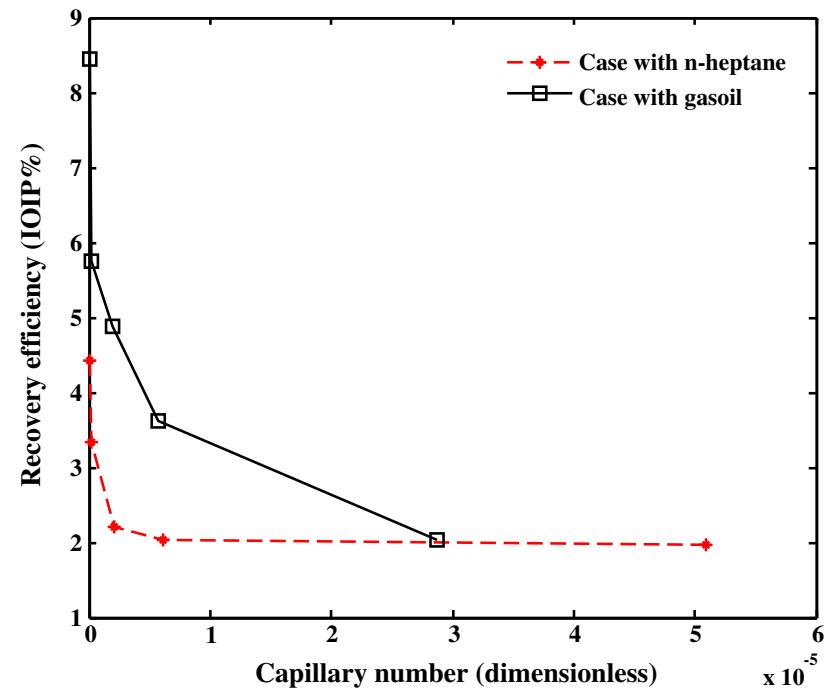

Fig. 4 Effect of capillary numbers on the oil recovery for two different oil phases at gas breakthrough

experimentally, it is calculated from the production rate, porosity, and connate water saturation (Chatzis and Ayatollahi 1993).

Figure 3 shows the recovery factors for different production rates based on gravity numbers, which confirms that as gravity numbers increase, the recovery factors also increase for both cases and approaches each other. Additionally, as the production rate increases, the gravity number decreases which finally results in lower oil recovery factor (see Table 4).

The effect of oil physical properties For a comprehensive investigation of the influence of oil physical properties, considering the effect of several parameters such as viscosity, surface tension, and density seems unavoidable. Hence, utilizing a dimensionless number by which all effective parameters and dominant forces on the gravity drainage process are taken into account could be practical. Therefore, the best dimensionless number which includes most variable parameters is the capillary number. This dimensionless number which describes the stability of the gas/oil displacement process is defined as the ratio of viscous force to capillary force, given in Eq. (3):

$N_{\mathrm{C}}=\frac{v_{\mathrm{o}} \mu_{\mathrm{o}}}{\sigma_{\mathrm{og}}}$

Here, $\mu_{\mathrm{o}}$ is the viscosity of displaced fluid (oil phase), $v_{\mathrm{o}}$ is the velocity of oil production and $\sigma_{\mathrm{og}}$ is the oil and gas surface tension. To maximize the efficiency of any EOR process, the capillary number value should be maximized (Green and Willhite 1998). Table 5 demonstrates the results of dimensionless capillary numbers for different oil phases and various production rates.

As it is obvious, among those experiments in which all properties except oil withdrawal rate were maintained constant, raising the production rate reduces the recovery factor at gas breakthrough. In fact, when pores were contacted and filled by the injected gas, the oil in the blobs spreads on water and creates oil bulk films between connate water and displacing gas (Carlson 1988). As saturation of bulk films of oil increases by continuing gas invasion, bulk oil films could flow under the action of gravity. However, increasing the oil withdrawal rate caused the viscous forces to become dominant compared to capillary forces, which led to instability in gas diffusion into the matrix part. This instability prevented oil accumulation at the advancing tips of gas-liquid interfaces and resulted in lower recovery factors. Furthermore, because of the higher viscosity of gasoil, lower capillary numbers were achieved and consequently more stable gas-injection front compared to $n$-heptane case were obtained. Hence, at the same production rate, the recovery factor for gasoil is higher than the one of $n$-heptane (see Fig. 4). 

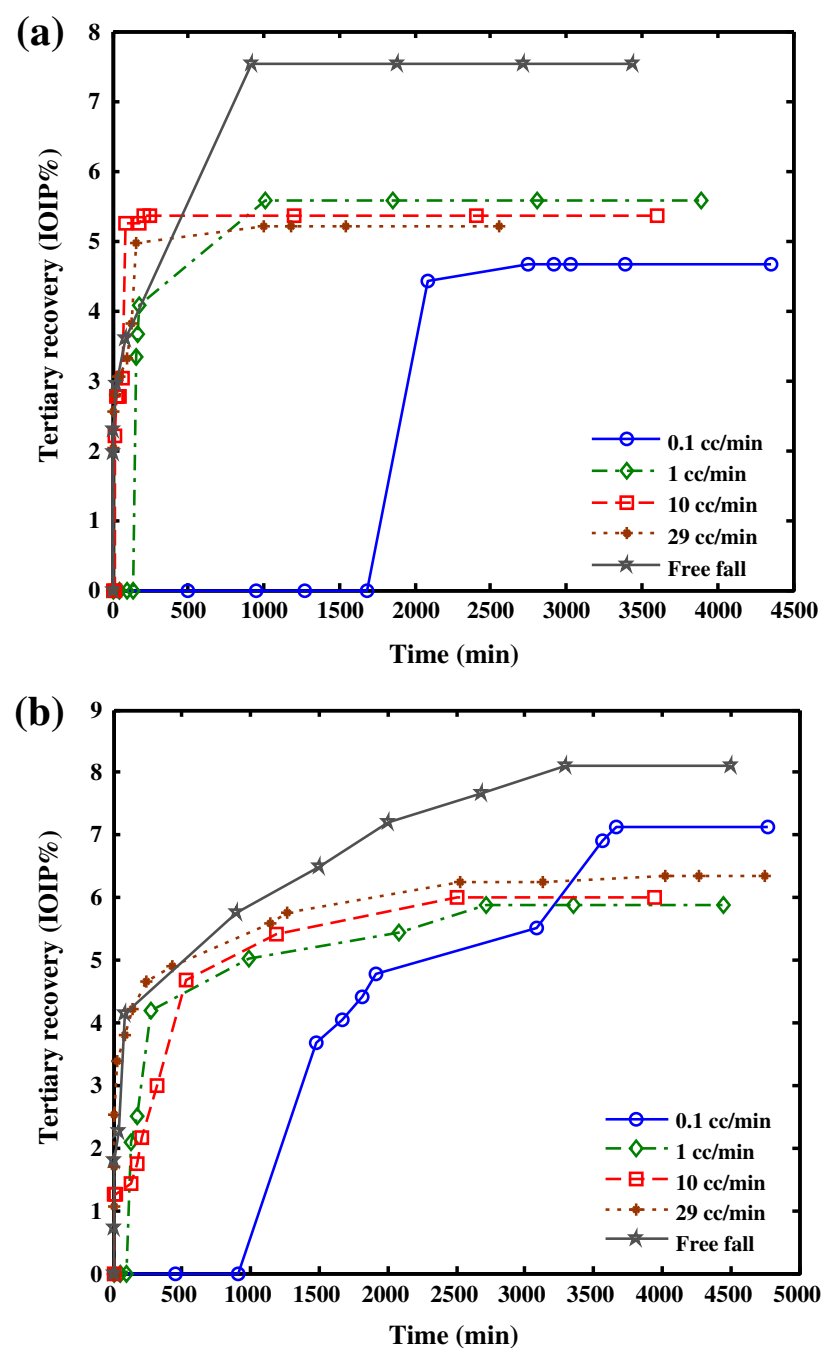

Fig. 5 Ultimate recovery factors in tertiary recovery process versus time for a high-permeable case ( 8.7 darcy), b low-permeable case (5 darcy)

\section{Oil recovery after gas breakthrough}

The effect of permeability As was explained before, reducing the permeability decreases the recovery factor at gas breakthrough time, which means higher amount of oil remained in the system. Therefore, for lower permeability cases (5 darcy), gravity forces were dominant which caused higher recovery factors for different production rates after gas breakthrough (see Table 3). Additionally, up to gas breakthrough, for lower withdrawal rates since viscous and gravity forces were more dominant than capillary forces, gas as the non-wetting phase occupied larger pores and pushed water into the smaller pores, which led to the production of more amount of oil and higher recovery factors. However, increasing the withdrawal rate caused early gas breakthrough, resulting in large amount of oil remaining in the system, and hence lower recovery
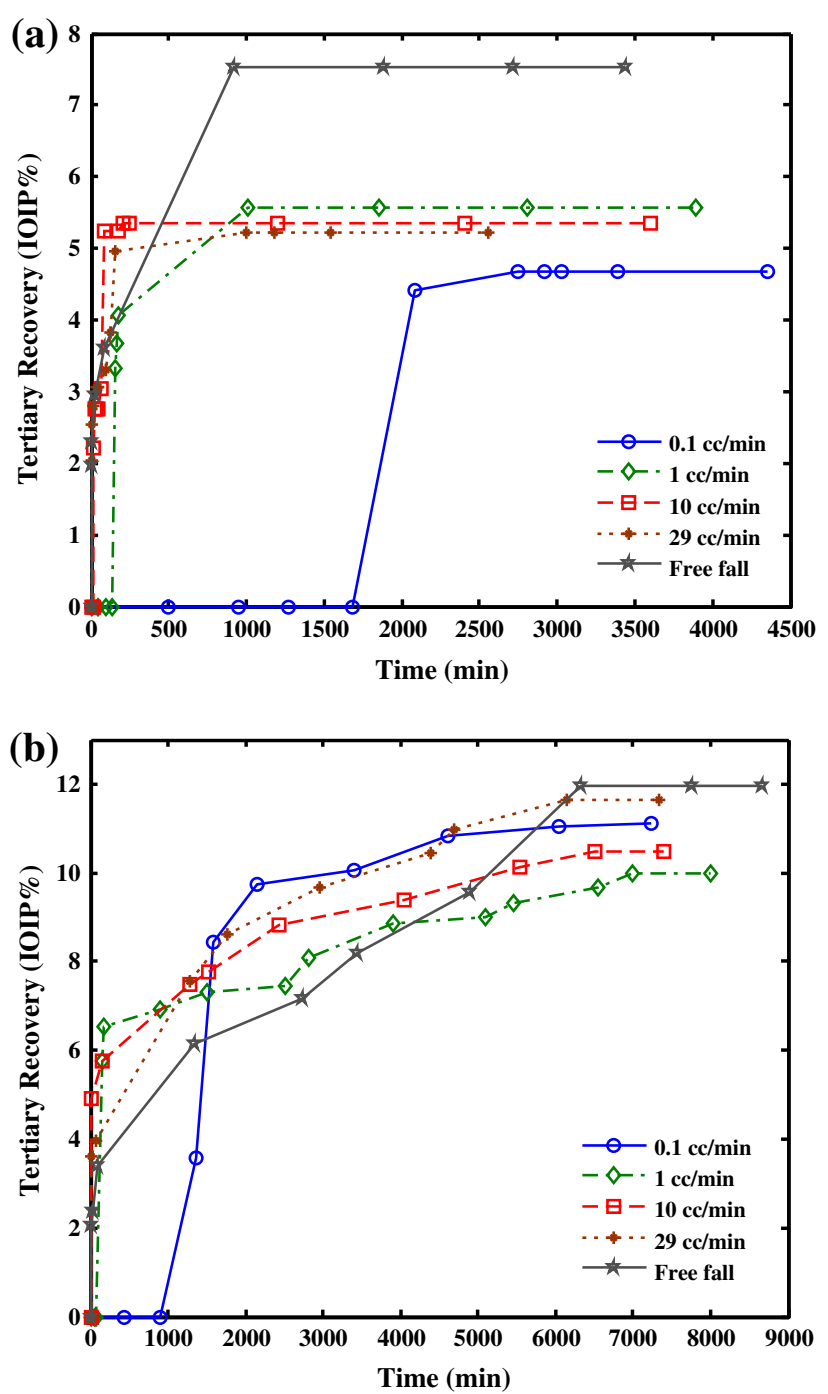

Fig. 6 Tertiary recovery efficiencies versus time for a $n$-heptane, b gasoil

efficiencies (see Table 3). Consequently, after gas breakthrough, for higher production rates due to the dominancy of gravity forces compared to capillarity, more oil was recovered. Hence, increasing the production rates results in an incremental trend of tertiary oil recovery after gas breakthrough, which brings the ultimate tertiary recovery factor to a reasonable value (see Fig. 5a, b).

The effect of physical oil properties Higher residual oil saturation after waterflooding process (see Table 3) and larger density difference between gasoil and the injected gas as compared to the case of $n$-heptane lead to larger gravity forces and consequently higher oil recoveries at various production rates for cases with gasoil (Experiment numbers 11-15) after gas breakthrough (see Table 3). In addition, during the tests using gasoil, the fracture was depleted faster and thus gas breakthrough as compared to the cases with $n$ - 
heptane occurred sooner. Similarly, after gas breakthrough, since less amount of oil remained in the system for lower flow rates, incremental trend of production rates caused an increase in oil recovery (see Fig. 6a, b).

\section{Conclusions}

In this study, experimental results were obtained in long visual laboratory model, for a single matrix block surrounded by vertical fracture. Experiments have been conducted using a wide range of physical and operational parameters, where the permeability of the porous medium, and oil physical properties as well as production rate were changed in order to acquire optimum oil recovery condition in secondary (waterflooding) and tertiary (CGD and FFGD mechanisms) recovery processes. According to the experimental studies and phenomenological analyses, the following conclusions are deduced:

- Waterflooding process followed by gravity-assisted gas injection was found to be an efficient scenario for oil production from fractured water-wet media.

- Matrix permeability, physical properties of oil, and residual oil saturation are important parameters that significantly affect production characteristics.

- Decreasing matrix permeability reduces the ultimate recovery significantly (secondary and tertiary recovery) while increasing oil physical properties such as viscosity or density leads to the raise of ultimate oil recovery.

- Reducing oil viscosity in water-wet fracture media made them favorable candidates for waterflooding process. However, this reduction leads to lower residual oil saturation at the beginning of gas-injection process which consequently, reduces the tertiary oil recovery efficiency.

- Production data of recovered oil by tertiary recovery mechanism (GAGD) under free fall gravity drainage and controlled gravity drainage conditions demonstrated that FFGD mechanism has achieved better performance compared to CGD process (especially in the systems with more viscous oil).

- Based on the physics of waterflooding and CGD process, and the experimental findings, gravity number, capillary number, and mobility ratio are the dominant dimensionless numbers to obtain an empirical model for recovery factor. Multivariate analysis can help in up scaling results for NFRs.

Finally, in order to advance our understanding of controlled gravity drainage in naturally fractured models, as well as to find out the interaction between capillary and gravity forces in the aforementioned process, the effects of various flow geometries, matrix properties, and model heterogeneity (i.e., shale barriers and fractures) on GAGD injection/production rate and oil recovery must also be investigated. Apart from that, development of an analytical or computational tertiary GAGD performance prediction model using a simple analytical model seems to be essential for fractured media during gravity drainage process.

Open Access This article is distributed under the terms of the Creative Commons Attribution License which permits any use, distribution, and reproduction in any medium, provided the original author(s) and the source are credited.

\section{References}

Ayatollabi S (1994) Experimental and theoretical investigation of gravity assisted inert gas injection for the recovery of waterflood residual oil. $\mathrm{PhD}$ thesis, University of Waterloo, Canada

Babadagli T (2003) Evaluation of EOR methods for heavy-oil recovery in naturally fractured reservoirs. J Petrol Sci Eng 37: $25-37$

Carlson LO (1988) Performance of Hawkins field unit under gas drive pressure maintenance operations and development of an enhanced oil recovery project. Paper (SPE/DOE 17324) presented at the SPE/DOE symposium on enhanced oil recovery, Tulsa, 17-20 Apr 1988

Chatzis I, Ayatollahi S (1993) The effect of production rate on the recovery of waterflood residual oil under gravity assisted inert gas injection. In: Proceedings of 5th petroleum conference of the South Saskatchewan Section, 18-19 Oct, The Petroleum Society of CIM, Regina, Saskatchewan (Paper no. 32)

Chatzis I, Ayatollahi S (1995) Investigation of the GAIGI process in stratified porous media for the recovery of waterflood residual oil. In: Proceedings of 6th petroleum conference of the south Saskatchewan section, The Petroleum Society of CIM, Regina, Saskatchewan (Paper no. 139)

Chatzis I, Kantzas A, Dullien FAL (1988) On the investigation of gravity-assisted inert gas injection using micromodels, long berea sandstone cores, and computer-assisted tomography. Paper (SPE 18284) presented at the SPE annual technical conference and exhibition, Houston, 2-5 Oct 1988

Da Sle WJ, Guo DS (1990) Assessment of a vertical hydrocarbon miscible flood in the Westpem Nisku D Reef. SPE Reserv Eng (May) 20:147-154

Dean RH, Lo LL (1988) Simulations of naturally fractured reservoirs. SPE Reserv Eng 5:638-648

Dullien F AL, Chatzis I, Macdonald IF (1990) Enhanced oil recovery process. Canadian patent no. 1304675 (July 1992), US patent no. 4953619 (Sept 1990)

Fassihi MR, Gillham TH (1993) The use of air injection to improve the double displacement process. Paper (SPE 26374) presented at the SPE annual technical conference and exhibition, Houston, 3-6 Oct 1993

Green DW, Willhite G (1998) Enhanced oil recovery, SPE text book series, vol 6, Chapter 1

Hagoort J (1980) Oil recovery by gravity. SPE J 20:139-150

Hinderaker L, Utseth R H, Hustad O S, Kvanvik B A, Paulsen J E (1996) RUTH—a comprehensive Norwegian R\&D program on IOR. Paper (SPE 36844) presented at the SPE European petroleum conference held in Milan, Italy, 22-24 Oct 1996

Johnston JR (1988) Weeks Island gravity stable CO2 pilot. Paper (SPE/DOE 17351) presented at the SPE/DOE symposium on enhanced oil recovery, Tulsa, 17-20 Apr 1988 
Kantzas A, Chatzis I, Dullien FAL (1988) Mechanisms of capillary displacement of residual oil by gravity-assisted inert gas injection. Paper (SPE 17506) presented at the SPE rocky mountain regional meeting, Casper, Wyoming, 11-13 May 1988

Kantzas A, Chatzis I, Dullien FAL (1988) Enhanced oil recovery by inert gas injection. Paper (SPE 17379) presented at the SPE/DOE symposium on enhanced oil recovery, Tulsa, 17-20 Apr 1988

Kulkarni M (2005) Multiphase mechanisms and fluid dynamics in gas injection. PhD thesis. University of Louisiana State, USA

Kulkarni MM, Rao DN (2006) Characterization of operative mechanisms in gravity drainage field projects through dimensional analysis. Louisiana State University, USA (SPE paper 103230)

Maroufi P, Rahmanifard H, Al-Hadrami HK, Escrochi M, Ayatollahi S, Jahanmiri A (2012) Experimental investigation of wettability effect and drainage rate on tertiary oil recovery from fractured media. J Porous Media 15(12):1111-1123

Nabipour M, Escrochi M, Ayatollahi S, Boukadi F, Wadhahi M, Maamari R, Bemani A (2007) Laboratory investigation of thermally assisted gas-oil gravity drainage for secondary and tertiary oil recovery in fractured models. J Petrol Sci Eng $55: 74-82$

Paillet FL, Hess AE, Cheng CH, Hardin E (1987) Characterization of fracture permeability with high resolution vertical flow measurements during borehole pumping. J Ground Water 25(1): $28-40$

Paul P, Zoback M (2007) Fluid flow in a fractured reservoir using a geo mechanically constrained fault zone damage model for reservoir simulation. In: Proceedings of the SPE annual technical conference and exhibition, Anaheim, California, 11-17 Nov 2007

Quintard M, Whitaker S (1996) Transport in chemically and mechanically heterogeneous porous media. Adv Water Resour 19(1):29-60
Rezaveisi M, Rostami B, Kharrat R, Ayatollahi Sh, Ghotbi C (2010) Experimental investigation of tertiary oil gravity drainage in fractured porous media. Special Topics Rev Porous Media (an Int J) 1(2):179-191

Rossen RH, Shen EI (1987) Simulation of gas/oil drainage and water/ oil imbibition in naturally fractured reservoirs. In: Proceedings of the SPE 16982, SPE annual technical conference and exhibition, Dallas, TX, 27-30 Sept 1987

Rostami B (2009) Mechanistic studies of improved oil recovery under forced gravity drainage GAGD process. PhD thesis, Sharif University of Technology, Iran

Salimi H, Bruining J (2008) Improved prediction of oil recovery from waterflooded fractured reservoirs. In: Proceedings of the SPE annual technical conference and exhibition, Denver, Colorado, 21-24 Sept 2008

Terwilliger PL, Willseya LE, Howard NH, Bridgeas PM, Morse RA (1951) Experimental and theoretical investigation of gravity performance. Trans. AIME 192:285-296

Van Pollen HK (1980) Fundamentals of enhanced oil recovery. Penn Well Publishing Company, Oklahoma

Zendehboudi S, Chatzis I (2008) Investigation of gravity drainage in fractured porous media using rectangular macromodels. In: Proceedings of the Canadian international petroleum conference/ SPE gas technology symposium joint conference (the Petroleum Society's 59th annual technical meeting), Calgary, Alberta, Canada, 17-19 June 2008

Zendehboudi S, Chatzis I, Shafiei A, Dusseault MB (2011) Empirical modeling of gravity drainage in fractured porous media. Energy Fuels 25(3):1229-1241 